Revista de la red interuniversitaria de estudios sobre las literaturas rioplatenses contemporáneas en Francia

7 | 2012

Arqueologías

\title{
La ocasión del poema
}

\section{Sergio Delgado}

\section{OpenEdition}

\section{Journals}

\section{Edición electrónica}

URL: http://journals.openedition.org/lirico/709

DOI: 10.4000/lirico.709

ISSN: 2262-8339

Editor

Réseau interuniversitaire d'étude des littératures contemporaines du Río de la Plata

\section{Referencia electrónica}

Sergio Delgado, «La ocasión del poema », Cuadernos LIRICO [En línea], 7 | 2012, Puesto en línea el 11 octubre 2012, consultado el 20 abril 2019. URL : http://journals.openedition.org/lirico/709; DOI :

10.4000/lirico.709

Este documento fue generado automáticamente el 20 abril 2019.

\section{(c) (i) (9)}

Cuadernos LIRICO está distribuido bajo una Licencia Creative Commons Atribución-NoComercialSinDerivar 4.0 Internacional. 


\title{
La ocasión del poema
}

\author{
Sergio Delgado
}

\section{NOTA DEL AUTOR}

Edgardo Dobry, rosarino, vive y escribe en Barcelona. Ha publicado : Tarde del cristal (Buenos Aires, Último Reino, 1992), Cinética (Buenos Aires, Tierra Firme, 1999), El lago de los botes (Barcelona, Lumen, 2005) y Cosas (Barcelona, Lumen, 2008). En 2005, de manera simultánea con la edición de El lago de los botes apareció, también en España, la reedición revisada de Cinética. Sus ensayos están reunidos en Orfeo en el quiosco de diarios (Buenos Aires, Adriana Hidalgo, 2007) y Una profecía del pasado : Lugones y la invención del « linaje de Hércules" (Buenos Aires, Fondo de Cultura Económica, 2010).

Esta conversación, como suele suceder en estos casos, comenzó antes de comenzar, es decir con la lectura de los poemas y los trabajos críticos de Dobry. Se continuó luego en una tarde de paseo por Nantes, escapando de una inhóspita Saint-Nazaire (puerto que cautiva desde hace años a los escritores argentinos) y en otros encuentros. Pero sobre todo por correo electrónico. Una primera versión estuvo lista en enero de 2006 pero una postergación editorial hizo que la publicación se demorara. Entretanto aparecieron otros libros y otras preguntas. La casualidad ayudó al carácter singular de este texto, acompañante del proceso de la escritura. No es accesorio por otra parte el hecho de que este reportaje implique viajes, distancias, esperas, que forman parte de los materiales con los que la poesía de Dobry trabaja.

S. D.

- Te fuiste a vivir a Barcelona en 1986, es decir a los 23 años y esta ciudad es sin duda importante en tu formación literaria. Pero, ¿qué significado tiene Rosario, a la que volvés periódicamente?

-Rosario es el centro de la espiral ; hace ya muchos años que no vivo allá pero, al mismo tiempo, nunca me voy del todo. De algún modo sigue siendo mi casa y a la vez, como es obvio, ya no la es. Esa rareza, esa diferencia, puede ser paralizante o, al contrario, un gran estímulo. No digo que sea fácil, pero para mí siempre fue más lo 
segundo que lo primero. Además, soy coetáneo de una generación muy brillante de poetas rosarinos o afincados en Rosario: Martín Prieto, Daniel García Helder, Beatriz Vignoli, Osvaldo Aguirre, Marcelo Rizzi, Pablo Makovsky, Oscar Taborda, Gabriela Saccone. Estar cerca de ellos, mantener un intercambio fluido con algunos de ellos, es imprescindible: porque yo me pienso en relación a ese "grupo", de una manera imaginaria, con toda la persuasión de lo imaginario. Ya no tengo la edad en que un poeta busca un comando en el que integrarse pero sigo necesitando el diálogo, escuchar lo que dicen mis amigos, saber en qué andan, qué leen y escriben, qué proyectos tienen.

- Vivís en Barcelona, donde hiciste estudios académicos y donde aprendiste los oficios de crítico, traductor y editor, todos ellos próximos del trabajo poético. ¿Qué relación mantiene tu poesía con esta ciudad?

-Llegué a Barcelona con la intención de pasear unos meses por Europa. Era enero de 1986 y, mientras esperaba la primavera para aventurarme hacia el norte, empecé a trabajar, casi sin quererlo. Los argentinos escapados de la dictadura estaban en la ciudad desde hacía diez años; gracias a ellos -Nora Catelli, Ana Basualdo, Graciela D'Angelo- empecé a hacer trabajo editorial y periodismo cultural. Para mí, en esa época, leer, escribir, hacer reseñas de libros o redactar artículos para enciclopedias era todo lo mismo, y de algún modo imprevisto la aventura me cautivó. Con el tiempo, el trabajo y la escritura se van escindiendo. Lo que quiere comprar un escritor, sobre todo, es tiempo libre : para leer y tomar, al hilo de la lectura, algún apunte. Pero todas las formas del trabajo - editar revistas, informar libros, traducir, comentar novedades literarias en la prensa- son emanaciones de la vocación poética. En una ciudad con decenas de editoriales, un oído más o menos fino para la palabra no es una virtud menos industrial que una mano diestra en habilidades tecnológicas. En cuanto a la poesía, es como el sol : no se la puede mirar de frente pero todo gira a su alrededor.

Veinte años más tarde la ajenidad perdura, con todos los matices que trae el tiempo. Para mí Barcelona fue y sigue siendo un lugar de concentración en el trabajo. No sé qué hubiera escrito si nunca me hubiera ido de Argentina pero creo que estar afuera me dio, paradójicamente si se quiere, una capacidad de centrarme, de concentrarme. Y, por supuesto, de ver otras cosas. Barcelona aparece en varios poemas míos como escenario, como "localización". En particular, en El lago de los botes, que tuvo la intención de ser un preludio autobiográfico, más parecido a un álbum de fotos que a una película en todo caso, Barcelona aparece en varias estampas intercaladas con la infancia rosarina y los viajes entre ambos polos.

Hice el doctorado en la Universidad de Barcelona. En los últimos dos o tres años, tardíamente, empecé a dar clases en esa misma academia. Este año voy a dar un curso de maestría en la UBA. Creo que nuestro perfil raro, descentrado, nos hace automáticamente comparatistas, y eso no me parece mal, porque da una perspectiva, un contexto ampliado sobre los asuntos estudiados, algo interesante en particular cuando se trata de literatura argentina.

-Tu tesis doctoral, según informa la solapa de uno de tus libros, tiene por tema "nacionalismo y lengua literaria en el Río de la Plata". Por otra parte el texto estudiado es El payador de Lugones. ¿Qué relación tiene este tema y este texto de Lugones en particular, con tu situación de poeta (viviendo en Cataluña) y con tu poesía?

-Precisamente ahora se acaba de publicar el ensayo que salió de la evaporación de esa tesis (Una profecía del pasado), quiero decir después de haberla exonerado todo lo posible de su paja filológica. A mí mismo me sorprendió, gratamente, que quedara un libro de doscientas páginas. Digamos que el bicentenario me sirvió de excusa para sacar ese 
trabajo que se refiere al Centenario, porque creo que fue más bien en torno a esa fecha, 1910, cuando se configuraron o "inventaron" - de ahí el subtítulo : Lugones y la invención del "linaje de Hércules" - varios de los rasgos de lo que será la identidad cultural, lingüística, literaria argentina. No partí de una idea previa : trabajé en la tesis como, de algún modo, lo hago también en los poemas : averiguando en la escritura lo que quiero saber, lo que todavía no sé. Quería entender, o tener al menos mi versión, acerca de cómo se había construido cierto capítulo o filón de la identidad argentina. Cómo se inventó la tradición como una "profecía del pasado". La lengua, en la genial y delirante fantasía de Lugones en $E l$ payador, es parte central de esa construcción. Vi que había cuestiones apuntadas pero no desarrolladas en la bibliografía; por ejemplo, la influencia de Nietzsche en el Lugones de esos años, que creo fundamental, porque en $E l$ Payador el gaucho termina siendo una versión tan peculiar como evidente del superhombre; que por otra parte era ya en Nietzsche, si hacemos caso a la aguda observación de Gramsci, un derivado de los personajes de Dumas y de Balzac.

La relación con mi poesía puede estar en la inquietud acerca de la lengua y de la capacidad del poeta para entender (en el sentido de comprender y de escuchar) el idioma de su comunicad, que a la vez recrea y reinventa. Es sabido que para un escritor vivir fuera de su ámbito de pertenencia es más complicado que para otros creadores, dado que el poeta se alimenta del idioma, de lo que escucha, de la índole del idioma que siente, algo relacionado con lo que suele llamarse "el acento" pero más intenso y abarcador. También es sabido que la situación puede ser particularmente problemática cuando se vive en un país en el que se habla la misma lengua que, a la vez, es del todo distinta. Pero, si es verdad lo que decía un gran romántico alemán, donde crece el peligro crece también lo salvador. Para mí lo salvador -bueno, la operación que intenté hacer- fue entender que la lengua de un poema es siempre una construcción o una reconstrucción, incluso cuando, como es el caso de los poetas más importantes de mi generación, se trabaja con el registro coloquial o conversacional, y de una manera, diría, radical. A lo largo de mi trabajo como poeta he intentado diversas modulaciones de esa composición, en ocasiones con un talante sardónico, superponiendo todas las hablas en lugar de seleccionar una (como en algunos poemas de El lago de los botes), en otras tratando de encontrar un registro que pudiera impactar con fuerza, como en los poemas de cosas, que son casi todos muy breves y exigían un grado bastante alto de condensación en todos sus elementos.

-Pese a vivir en España, tus primeros libros los publicaste en Argentina. En 1992 se publicó Tarde del cristal y en 1999 la primera edición de Cinética. ¿Había una necesidad particular de publicar en Argentina?

-Mi primer libro salió en Último Reino de una manera casual: conocí a Víctor Redondo, que era el editor de ese sello, durante un congreso sobre poesía latinoamericana en la Universidad de Salamanca, al que yo había ido como mero oyente. Eso debe haber sido en el año 90 o 91. Creo que fue el primer editor de poesía que conocí, después fui a verlo en Buenos Aires y concretamos la salida de mi libro. En cuanto a Cinética, fue Daniel García Helder quien me puso en contacto con José Luis Mangieri. Lo llamé, me citó en un bar de comida rápida en avenida Corrientes, con un aire como semiclandestino, enfrente de la librería Ghandi. Yo le di el manuscrito y unos meses más tarde salió el libro. En ese momento no se me pasaba por la cabeza la posibilidad de publicar un libro en otro lado que no fuera Argentina. Si más tarde salieron dos libros míos en Barcelona fue porque ya hacía suficientes años que vivía en 
la ciudad como para conocer un poco más de gente y, a la vez, era más fácil para mí que buscar un editor en Buenos Aires.

- Los poemas, en tus libros, no están fechados (ya hablaremos más adelante de tu trabajo de re-escritura) y parecen ser siempre "actuales". Lo que te quería preguntar es, en relación con tus primeros poemas, si ya escribías poesía antes de irte a Barcelona; si por ejemplo hay poemas que escribiste o comenzaste a escribir en Rosario, antes de irte.

-Sin duda en mi primer libro hay restos de papeles traídos de Rosario. Hay poemas empezados en Argentina y terminados en Barcelona, cosa que no es accidental pues en cierto modo marca el ritmo de casi todo lo que escribí, en ese vaivén. No es casualidad que en El lago de los botes, donde la oscilación es casi el eje del libro, hay un poema dedicado al viaje en avión. En todo caso, hasta donde yo mismo puedo saberlo, mi escritura cuaja en Barcelona como lugar de la inadecuación : no hay relación natural con el medio y en ese décalage se abre la grieta del poema. No hay encajes fijos, hay circulación, líneas cruzadas de filiaciones : eso aparece, o quise que apareciera, en $E l$ lago de los botes.

- Tu poesía, indudablemente, es leída desde los hábitos y tensiones de la crítica argentina. Pienso en particular en las reseñas que se escribieron sobre Cinética en el momento de su aparición, es decir en 1999-2000. Por un lado un poeta como Ricardo Herrera ("Del movimiento y la inmovilidad", en Hablar de poesía) lee el libro en función de la polémica que él mantiene con los poetas llamados de los 90 y la utilización que hacen del registro coloquial en poesía. Plantea concretamente que vos lográs "una solución al conflicto entre lo sublime y lo vulgar". En un estudio sobre la tensión que se genera en las revistas literarias del momento (particularmente Diario de poesía y Hablar de poesía), Ana Porrúa analiza la crítica de Herrera y establece que, en realidad, este crítico está más inclinado a leer en tu poesía "lo sublime" que "lo vulgar". Por otra parte, poetas como Alejandro Rubio u Osvaldo Aguirre leen Cinética ubicándolo en otro orden genealógico, en un marco digamos "objetivista" y de esta manera poniéndolo del lado de poéticas como la de Daniel García Helder o Martín Prieto. ¿Cómo ves estas lecturas y estas polémicas ? Alguna importancia le das porque hay citas de fragmentos de las mismas en la contratapa de la segunda edición de Cinética.

-Desde afuera, por afuera yo me siento cercano a lo que escriben mis compañeros de generación, como los que vos acabás de mencionar. Tuve que reconstruir eso en una escena virtual, lejos de donde ocurría. Pero nos movían inquietudes parecidas, sobre todo, si no me equivoco, alejarnos del neobarroco de los ochenta y encontrar un registro que, sin renunciar a una intensidad lírica, se construyera de un modo menos "artístico" : mirando hacia afuera, diría. O mirándose desde afuera. Ahora bien, creo que si Cinética quedó en medio de cierto fuego cruzado entre dos revistas -cosa que, por supuesto, no me molesta en absoluto, todo lo contrario- fue porque participaba de ambas tendencias. Es decir, creo que tenía ese perfil bajo, cotidiano, experiencial, pegado al mundo material que es propio del objetivismo ; pero a la vez, creo, mostraba cierta preocupación técnica, dejaba ver un entrenamiento en el verso clásico que muchos poetas del objetivismo no tenían ni querían tener. Sin embargo, en un libro absolutamente central de la poesía de los noventa, como es El guadal de García Helder, la destreza de la sintaxis y la acentuación es del todo clásica. No hay nada canyengue en Helder, como tampoco lo hay en Prieto ni en Aguirre, ni, seguro, en mis poemas. Quizás nuestra región, eso que podríamos llamar el litoral fluvial argentino, tiene una cierta reluctancia a la aspereza de la dicción, una cierta inclinación por la modulación temperada, cosa que no me parece reñida con el intento de escribir poesía contemporánea. 
- Me llama la atención la diferencia en la lectura de Rubio y Herrera de "Altura", el primer poema de Cinética. En particular del último verso : "Mas justo lo difícil, ese puente". Herrera lee "puente" en el marco semántico de lo abstracto y lo sublime. Habla, concretamente, de tu "don para poner en órbita, para hacerle alcanzar altura poética ('lo difícil, ese puente') a la palabra que lleva a cabo esa operación literaria". Por otra parte Rubio lee este verso en clave más bien objetivista y dice : "el deíctico 'ese' señala una posición del yo lírico, diseña sutilmente una escena que nos está hablando en sentido figurado, es claro, pero casi podemos ver a alguien en una orilla señalando hacia la mentada obra del ingeniero". Es cierto que toda palabra genera y acepta una pluralidad de sentidos y es probable que ese verso habilite ambas lecturas. Por eso, sin pedirte que desmientas estas críticas ni que me des instrucciones para leer ese verso, me gustaría conocer tu opinión.

-Esta discrepancia que mencionás parece casi un chiste borgiano, en tanto el crítico reescribe el poema que analiza, aunque sin duda no hay mayor halago para un poeta que recibir dos interpretaciones distintas y a la vez tan bien argumentadas. Es posible que en mis poemas lata una cierta nostalgia formal, en el sentido de que pienso el poema como un objeto deliberado, como algo construido en el intento de resolver un problema o una dificultad estética. Por eso me gusta que Rubio haya hablado de "ingeniería", cosa que, si lo pensamos un poco, no está tan alejada de lo que Herrera llama "operación literaria". Ambos están mirando los tornillos del poema, los procedimientos mediante los cuales un poema busca cierto efecto en el lector. Un lector más o menos ingenuo dice, por ejemplo, "este poema me transmite una sensación de claustrofobia o de encierro urbano o de desazón a la caída de la tarde". El crítico -en el caso del que estamos hablando, los dos críticos son además poetas- se pregunta por el modo en que eso sucede, por el mecanismo, la operación o la ingeniería que hay detrás de ese efecto. Desde mi punto de vista, hay muy pocos buenos poemas que no tengan algo de eso.

- En esas críticas se señala en tu poesía, por otra parte, la rara instancia desde la cual habla el yo lírico. Puede ser un prejuicio dado que todos estos críticos saben que vivís en Barcelona. De todas maneras en el primer verso del poema "Cinética", que da título al libro, se lee : "Quedarse quieto aquí :". Ese "aquí" parece siempre de difícil resolución en tu poesía.

-Sí, el "aquí" es un lugar movible. Es un lugar gramatical más que físico. Sin embargo no deja de ser un lugar cerrado. Ese poema habla, en cierto modo, de la imposibilidad de quedarse quieto y de la dificultad de moverse, del equilibrio imposible entre las dos cosas.

-En 2004 aparece una nueva edición revisada de Cinética, tu segundo libro ; aquí lo viejo se presenta, según una nota del autor, como "una nueva versión", como un intento de hacer avanzar el poema "en la dirección que su propio movimiento [...] parece indicar". ¿Qué sentido tiene la noción de poema y de movimiento en el trabajo de reescritura?

-Cinética es un título que alude al movimiento, y por lo tanto, también, a la quietud. Pero no sólo al movimiento y a la quietud del sujeto que habla en el poema, sino a la del poema mismo. Soy de la idea - quizás esto tiene que ver con esa cierta aspiración clásica que mencionaba antes- de que un poema nunca está acabado. Yo sigo corrigiendo siempre. Ahora, por ejemplo, al hacer lecturas de los poemas de El lago de los botes y de cosas sigo corrigiendo, sacando aclaraciones innecesarias, cambiando adjetivos superfluos o demasiado oscuros. El verso libre busca su estado ideal en un movimiento perpetuo, porque nunca está clavado, porque los otros versos no lo sujetan. Pero como esto le pasa a todos los versos, es el poema entero el que oscila, como una marioneta. En ese breve prólogo de la edición madrileña de Cinética intentaba decir que cada poema tiene una fijeza en su por qué y una permanente oscilación en su cómo. 
- Se puede pensar que hay dos direcciones de tu trabajo de reescritura de poemas. Por un lado en relación con el ritmo y la forma poética, hay como un movimiento general que, paradójicamente, va de lo complejo a lo simple. Por ejemplo es lo que ocurre con una corrección de la primera estrofa del poema "Altura" de Cinética. Así queda en su última versión : "Impacto de lo estrecho en la vía recta : / si se besan la punta de los codos / oreja es una flor en cada mano." En la primera edición, en el segundo verso se leía "las puntas". Ese triángulo particular que conforman los hombros, las manos y las puntas de los codos unidos, ese abrazo a sí mismo, en el vacío, parece definirse y sintetizarse con el uso del singular. En ese verso endecasílabo, el sintagma "la punta", ocupa además su centro geométrico (sus extremos : "si se besan" y "de los codos", a ambos lados, computan cuatro sílabas. Si lo que digo es correcto : ¿qué busca la corrección de ese verso ?

-Parece increíble que haya lectores como vos que se detengan a apreciar esas cosas. Es tu lectura la que hace el poema: porque ahí vos atrapás lo que yo intentaba explicar antes : el poema como objeto construido con una noción estética. Ahí está, creo, lo que Rubio llamaba "ingeniería". En el paso de un plural a un singular es donde puede cincelarse esa aspiración : la búsqueda del símbolo. Es decir, una compleja combinación de lo ambiguo con lo preciso, de lo flotante con lo fijamente anclado.

-Siguiendo con la corrección, me parece que hay, por otra parte, un trabajo ya no en función del ritmo sino de las imágenes. Esto fue señalado por Samoilovich en una presentación de tu poesía en la que recuerda un paseo que hizo con vos a un lago, en Rosario, que es el referente espacial del poema "El lago de los botes". En este paseo, dice Samoilovich, hubo una conversación sobre la nomenclatura de unas columnas que estaban junto al lago. El resultado de esta conversación fue luego incorporado a una revisión del poema. Esto lleva a Samoilovich a caracterizar tu manera de componer el poema como "imaginista" (bueno, supongo que el término podría discutirse) y además a una reflexión sobre los espacios y su representación, que me parece muy interesante. Dice "Para el que vive lejos de donde transcurrió su infancia, los lugares han perdido naturaleza, parecen todos inventados; los nuevos, porque son fruto de una acción, llámesela viaje o emigración o exilio, los viejos porque el comercio regular con ellos ha quedado interrumpido, confiado a la memoria". ¿Qué podés decir de esta relación entre la corrección y la imagen ; y en particular entre la corrección y el espacio?

-Esto remite al expediente de la inadecuación. Creo que Samoilovich acierta : hay una forma de artificiosidad en la reconstrucción de los espacios. Pero, ¿existe, acaso, lo contrario ? Digo, en poesía, ¿cuál sería la manera natural de reconstruir el escenario de una determinada anécdota o acontecimiento ? Lo que yo hacía, en ese paseo por el Parque Independencia, era contrastar mi idea de memoria, desde lejos - desde afueradel laguito con la visión directa del laguito. Pero cuando volví a Barcelona y retoqué el poema no quedó más natural ; más bien lo contrario. Por ejemplo: le agregué"... columnas / con capiteles corintios que no sostienen nada" (que existen), y también : "un cisne rechoncho de cemento, / el cuello de alambre ya pelado / y retorcido varias veces" (que es un invento). ¿Por qué ? Es una broma evidente con el famoso "Arte poética" de Enrique González Martínez: "Tuércele el cuello al cisne de engañoso plumaje" ; ese sólo verso, de 1911, es el primer manifiesto antimodernista. Pero lo curioso es que poca gente se dio cuenta de que ese cisne es inventado : quizás porque es verosímil, o quizás porque el lago de los botes es otro "aquí" movible. En el Hyde Park de Londres, en el Bois de Boulogne de París, en el Central Park de Nueva York, en el Tiergarten de Berlín y en otras mil ciudades también hay laguitos artificiales donde la gente, sobre todo los adolescentes, van a remar. Ese estar abordo en el corazón mismo de la ciudad es una primera experiencia del viaje soberano. Esos laguitos representan, dentro de las ciudades, espacios de naturaleza reconstruidos artificialmente: son artefactos en sí mismos. Y a mí me llamaba mucho la atención que, en una ciudad 
rodeada de campo, río majestuoso e islas, nuestra experiencia de la naturaleza fuera un lago artificial ; hay algo del encierro ahí también. Pero todos esos laguitos son símbolos, son emblemas del aburrimiento y de la artificiosidad. Por eso me gustaba que el cisne de cuello retorcido aludiera al mencionado González Martínez, quien a su vez alude a Darío ; pero también a Baudelaire, al cisne manchado de barro, emblema tremendo del fastidio, del embotamiento urbano. Y me gustaría mencionar también un poema de $E l$ guadal, de Helder, en el que de pronto emerge del agua de una zanja, "intacta", una "cabeza de perro". Ese poema, que Helder ubica en "extramuros", como si Rosario fuera una ciudad medieval y el barrio de Alberdi quedara fuera de la muralla, crea una zona indecisa entre lo urbano y lo rural, cercana a la calle sin vereda de enfrente, pero contemporánea y siniestra, violenta y traumática en lo "intacto" de esa cabeza de perro que emerge de golpe. Emerge a la vez de la zanja y de la memoria, monstruosa en su amplificación.

- Prolongando las anécdotas, recuerdo que en un paseo que hicimos por Nantes, de vez en cuando sacabas una libreta para anotar algún dato. Esto está en relación con la condición del viajero en tu poesía, tanto la de quien recorre un territorio extranjero (Francia en "Blues turístico", Italia en "San Pietro in Vincoli" o España en "Fotógrafos en el monasterio") como la de quien regresa al espacio propio ("El lago de los botes" o "Asado en Soldini"). Todos los poemas mencionaos pertenecen a El lago de los botes, libro donde este rasgo se acentúa. ¿Qué pensás en relación con este tema: se trata de poemas que se buscan o que, simplemente, te sobresaltan a la vuelta de una esquina ? Después de todo la libreta existe, yo la vi...

-Te insinuaba antes que Cinética es un título ambiguo, porque en realidad es un libro sobre la quietud. El lago de los botes, que sitúa en el centro un paisaje de infancia, tiene que ver con la movilidad : más que con el viaje, diría que con los diversos afueras en los que orbitamos: afuera de la infancia, del origen, de una nítida identidad comunitaria, ideológica o incluso estética. Afuera incluso del mismo lugar donde vivimos, porque, en tanto ya no se vive en el lugar de origen, se habita en un afuera perpetuo. Cinética es un libro de encierro ; El lago de los botes, tal vez, es un álbum de intemperie : de una falta de pertenencia o de una superposición de varias pertenencias borroneadas, aunque sin pretensiones solemnes, claro. El viaje como imposibilidad de entrar, de encontrar una entrada.

La libreta existe, sí, porque un aprendiz de escritor siempre ha de llevar una libreta. Me acuerdo ahora de una entrevista a Arnaldo Calveyra, en Argentina. En un momento dado la periodista le dice : "Su parquedad ante el uso de los adjetivos me recuerda una frase de Huidobro : 'El adjetivo cuando no da vida mata'". Y a Calveyra le gusta tanto la cita que, en lugar de contestar, saca una libretita y se pone a anotarla -con esa parsimonia entrerriana que sus muchísimos años parisinos no le pulieron-, ante el azoro, supongo que merecidamente vanidoso, de la periodista (dicho sea de paso: solamente una periodista argentina puede tener el talento literario de hacer esa pregunta, con la cita incluida). La libreta es como una bolsa en la que uno va juntando todo lo que encuentra para después seleccionar. De la anotación más banal puede salir un poema "importante". A mí me pasó varias veces, por ejemplo hay un poema de $E l$ lago de los botes, "La visita de padre", que sale de unos apuntes tomados por causalidad de las observaciones bastante disparatadas de mi papá sobre un postre muy popular en Barcelona, el brazo de gitano, y de los equívocos a que eso dio lugar. También, a veces, a uno se le ocurre un verso, o dos, que pueden ser el origen de algo, y hay que anotarlos de inmediato porque su origen es sobre todo rítmico, no tiene tanto que ver con una idea como con una serie de acentos y vocales, algo así, una fórmula difícil de retener en 
la memoria. Digo, si es cierto que existe la inspiración entonces tiene que haber algo en el aire que uno interioriza con cierta acentuación del esfuerzo respiratorio, y ese aliento, si no te agarra precisamente en el lugar de trabajo, sólo puede encerrarse provisoriamente en una libreta.

- La aparición casi simultánea en 2005, en España, de El lago de los botes y de la segunda edición revisada de Cinética, vuelve contemporáneos poemas escritos en tiempos y contextos diferentes. Sin embargo, se me ocurre que el lector español que accede a tu poesía a partir de estas ediciones se sentirá descorazonado: ambos libros, en lugar de sostener la actualidad del poeta, a la que aspiran por la escritura o la re-escritura, trazan sin embargo un movimiento hacia el pasado, a determinados hechos y ámbitos del lugar natal. ¿Qué conciencia o impresión tenés de ese movimiento ?

-En la presentación de El lago de los botes en Barcelona, Antoni Martí Monterde, escritor en lengua catalana -por otra parte, autor de un conmovedor libro de viajes por Argentina-, dijo algo que a mí me gustó particularmente : que él veía El lago... como un libro escrito al mismo tiempo en dos lugares. Es decir, no como una nostalgia de Argentina desde Barcelona sino - esto ya son mis palabras- como una pertenencia a ambos lugares y por eso mismo rara o singular en ambos casos. Yo traté de que esto se vea en la lengua: por ejemplo, en "La cuestión del chocolate", que representa una escena enteramente barcelonesa, se espera el autobús. Pero en "Correspondencias", el viaje entre Buenos Aires y la Ciudad Nativa se hace en colectivo. Cada variación de ese registro indica, como en una especie de oscilómetro, un pasaje de un mundo al otro. Creo que un poema autobiográfico se construye con elementos equivalentes a los que un artista utiliza en un autorretrato : está, digamos, el objeto que uno ve o quiere ver, y está la manera de representarlo o de representarse.

- Hay en El lago de los botes un trabajo con los sustantivos. Por un lado hay una apertura hacia ciertos nombres ligados, por ejemplo, a tu origen judío. Ciudades como Tel Aviv, personajes como el abuelo Moshé o palabras como "Sheide". Por otra parte se percibe una suerte de restricciones o prohibiciones: la ciudad de Rosario nunca es nombrada en tu poesía y en cambio aparece referida, con insistencia, bajo el nombre de Ciudad Nativa. Recuerdo en este momento que en la obra de Saer, que te es muy próxima, cuyo centro referencial es Santa Fe, el nombre nunca aparece : se la nombra como Ciudad o como La Zona. ¿Este trabajo de selección de las palabras es deliberado?

-Sí, es un ejercicio cercano al de Saer. Curiosamente, en Saer no aparece el nombre de Santa Fe, pero sí Rosario y, por supuesto, París : los lugares a los que se tiende. Supongo que es algo parecido a lo que hacía Onetti al inventar Santa María, y tantos otros miembros del círculo de Jefferson. En mi caso, lo de Ciudad Nativa quiere tener un tinte humorístico, en esa visible agramaticalidad. Nativo como natal, como aborigen y como algo recientemente nacido. Igual, la intención es la misma -quizás la intención poética por excelencia : buscarle un sentido universal a una experiencia individual. De todos modos, lo de Ciudad Nativa es algo que forma parte de El lago de los botes. En Cosas sí aparecen denominaciones claramente vinculadas a Rosario, como el barrio de Pichincha o el Boulevard Oroño, escenarios de visiones o de experiencia, quizás porque Cosas es un libro menos humorístico que El lago... y se prestaba menos a esos juegos, o quizás porque esas visiones necesitaban, o yo creí que necesitaban, un anclaje concreto y bien delimitado. 
-En el poema "Asado en Soldini" de El lago de los botes se dice : "no sé cómo se puede / no vivir acá, no vivir aquí". En una construcción, como decíamos, planteada desde el retorno, el "aquí" cambia de perspectiva...

-Sí, pero del retorno a un lugar como tendencia perpetua, no como acto cumplido o por cumplir. El retorno como polo magnético, con la consciencia de que ese lugar, como todo origen, también está perdido. En mi experiencia, el paisaje de origen se hace del todo visible cuando se llega a él desde afuera : hay que haberlo dejado para poder verlo, en el sentido fuerte del término (como epifanía, si se quiere : es decir como presencia completa, que adquiere en la escritura un espesor estético y moral). Los grandes mitos de los que estamos hechos, como la expulsión del Paraíso o el viaje de Ulises -en ambos casos, nostalgia de un origen, de una adecuación completa al "aquí"- no son cosas sucedidas en un pasado remoto: son cosas que suceden continuamente, que están sucediendo ahora mismo. Hay un aforismo de Kafka que dice algo así.

- Tomando de alguna manera tus propias palabras, me refiero a la "Nota del autor" de la segunda edición de Cinética, cada poema realiza un movimiento dentro del círculo en el que está encerrado y a su vez ambos libros trazan también un movimiento circular que acompaña al trabajo de la memoria. ¿Qué relación de autonomía mantienen tus poemas en el interior de cada libro ? ¿Cómo pensás la construcción de la unidad de los libros ?

- Cada libro es para mí un proyecto cerrado, en el sentido de que intento no repetirme. Es la idea de "ocasión" de Montale, ¿no ? Él decía que un poeta no debe gastar su voz en cuatro o cinco poemas cuando, con uno solo, ya da cuenta de la ocasión a la que el poema responde. Yo creo además que, en tanto trabajo artístico, el poeta debe tratar de hacer lo que todavía no sabe hacer, porque seguir haciendo aquello en lo que ya adquirió una cierta destreza es repetirse y resignarse, como mucho, a lo correcto. En El lago... había esencialmente dos haces, dos movimientos: uno horizontal -que se espirala oscilaciones de paisaje, el ir de un mundo a otro- y otro vertical -la línea de la filiación : el poeta como hijo y como padre-. Ambos ejes se reflejan entre sí, claro, pero no de un modo mecánico, pues se producen diversos cruces y complicaciones deliberadas.

En cuanto a la idea de cada libro como un proyecto distinto me gustaría agregar un matiz : el hecho de que sea así no es del todo una decisión sino una forma de trabajo que se me impone. Mientras estoy escribiendo un libro todo lo que se me ocurre oscila en esa frecuencia, adopta automáticamente la forma de ese proyecto, su estilo o humor. Cuando me parece que ya está y lo doy por terminado, incluso aunque siga corrigiendo cosas, ya no me "nacen" flecos en esa misma línea. Por lo general, en cuanto publico un libro de poemas empiezo a pensar en otra cosa, a tomar apuntes (la famosa libretita de Nantes sale otra vez a relucir) y por algún lado vuelve a aparecer una punta del ovillo de la que ir tirando, aunque ya en otra línea distinta de la anterior. Son como máscaras, un poco como hacía Pessoa, sólo que sin inventarles nombres dado que nunca son proyectos simultáneos sino sucesivos.

- La aparición en 2008 de Cosas, tu cuarto libro poético, parece justificar la afirmación anterior. Es decir que en este libro hay una ruptura con lo anterior. En la contratapa se habla, incluso de "una concepción poemática radicalmente distinta". Es cierto que parece haber otra medida poética : se trata de poemas breves, sin título, que buscan fundirse en el conjunto. Me gustaría saber lo siguiente: ¿cómo es la vivencia (o si se quiere, la convivencia) de esos dos estados tan distintos del poema?

-Fueron libros sucesivos, no hubo simultaneidad. El lago... se publicó en junio de 2005 y lleva una dedicatoria a Juan José Saer, que acababa de morir. Un poco más tarde 
enfermó mi madre, y murió en febrero de 2008, es decir unos meses antes de que el libro estuviera terminado. En ningún momento decidí que cosas fuera un libro sobre el dolor por la pérdida de seres muy cercanos y queridos, fue casi una sorpresa para mí darme cuenta de que esa experiencia mía había dado el color del libro. A decir verdad la primera idea de cosas era retomar una línea que fue muy importante para mí en mis primeros años de lector de poesía : el dominio italiano, esa forma particular de lirismo amargo y árido de Montale, Sbarbaro, Bertolucci, Sandro Penna... Son poetas muy distintos, y dentro de la obra de cada uno hay momentos y cosas muy diferentes también, pero hay algo en ellos que vibra en una misma onda. En los poemas largos es casi inevitable que la palabra se diluya un poco en la extensión, porque un poema largo necesita músculo para sostenerse y por lo tanto tiene que fluir. En cambio en la forma breve cada palabra puede esgrimir todas sus resonancias, sus matices y caras. No tiene nada que ver con el haikú ni con nada asiático, que se puso de moda en las últimas décadas, sino con una larguísima tradición occidental, diría, más restringidamente, mediterránea, que se remonta a la Antología Griega y a los epigramas latinos. Esa forma es a la vez lírica y sentenciosa, que tiene algo de canción popular y de aprehensión fuerte del concepto, como si uno asistiera a la encarnación de la idea.

- Los poemas no tienen título, sólo un número. Algunos, como mínima indicación, dan un dato (un lugar, un nombre). El poema 30 indica, a modo de título : "final de soneto". Se trata de seis versos (dos tercetos) que, como el fragmento de un poema encontrado en un libro, parecen ser los últimos versos de un soneto perdido. El último verso es un alejandrino. Me hace pensar en el soneto de trece versos de Darío, donde el último verso parece desintegrarse. ¿Qué relación hay entre esta pérdida de la forma y la suerte del poema como unidad en este libro?

-Diría que puedo contestar esa pregunta más como crítico, como lector de mi propio libro, que como autor. Creo que cosas es, en parte, un conjunto de poemas sobre la desintegración, sobre la dificultad del orden completo, sobre la clasificación provisoria. Son poemas como restos, que se proponen hacer del lector una suerte de arqueólogo intuitivo. Así como el arqueólogo reconstruye la forma $-\mathrm{y}$, por lo tanto, la función- de una vasija arcaica a partir de un fragmento hallado en una excavación, unos pocos versos pueden dar el clima, la intención, la ocasión de la unidad perdida en la que se integraban.

-En 2007, en una conferencia, Nora Catelli decía : "los poemas de Dobry se inscriben en [un] espacio de interrogación. Cuando la forma se vuelve esquiva -y ésa es la característica de nuestro tiempo- el pensamiento de la forma provee de los instrumentos para atraparla y transformar la lectura -que es siempre una operación sobre el pasadoen el procedimiento para restaurar el impulso de la búsqueda." ¿Qué podés decir de esta afirmación y cómo la inscribís en el movimiento que va de El lago... a Cosas ?

-Bueno, creo que tiene algo que ver con lo que acabamos de hablar, ¿no?, del fragmento como resto $\mathrm{y}$, a su vez, generador de la unidad completa, que ya está perdida. Nosotros conservamos una cierta inteligencia formal que reconstruye el movimiento a partir de su impulso, el color a partir del matiz, el tono en la nota. Creo que a algo de eso se refiere Catelli con la idea de "forma esquiva". Si el propio Darío decía "yo persigo una forma..." ; de todos modos se sabe que nosotros, de la forma, sólo podemos tener la nostalgia. La forma es universal y la nostalgia es subjetiva. A pesar del símil arqueológico anterior, no hay reconstrucción objetiva sino la insinuación de un croquis tentativo. A mí me parece que en cierto modo es una tensión que atraviesa los últimos cien años. Eliot escribe un breve ensayo sobre Ulises que titula "orden y mito", donde dice que la grandeza de Joyce consiste en haber sujetado la tendencia al caos 
propia del arte y la literatura de su tiempo en el molde más o menos maleable del mito clásico. Apollinaire, en Alcoholes, transcribe conversaciones de porteras de París, pero las pone en alejandrino, jugando con la relación entre fondo y forma, entre tradición áurea y asunto banal. A mí siempre me atrajeron mucho más estos experimentos que la mera profusión surrealista, eso que Gabriel Ferrater llama "el movimiento de las grandes masas de líquido verbal". Si, de algún modo, estamos condenados a navegar por esas corrientes, que lo hagamos con una idea de hacia dónde vamos, sin hacer la apología del naufragio. Por eso, en lo que llamás "el movimiento que va de El lago... a cosas", hay esa búsqueda de un derrotero cuyo origen o cuyo principio está siempre adelante, siempre por venir. "El origen - dice Walter Benjamin - no designa el devenir de lo nacido, sino lo que les nace al pasar y al devenir". Es decir que, tanto en la experiencia individual como en la trayectoria estética, todo movimiento cíclico, tensado a la vez hacia adentro y hacia afuera y recibe su impulso de ese principio perdido. Ese proyecto de origen es el motor de toda concreción formal.

-En Cosas parece borronearse lo que anteriormente llamabas "línea de filiación" (muy presente en El lago de los botes). Esta línea, muy ligada a lo paterno o a la paternidad, se modula ahora en torno de la figura de la madre. Pienso concretamente en los poemas 33 y 77 (títulos que, curiosamente, repiten una misma cifra, por cierto que muy significativas las dos : 3 y 7). Otra curiosidad, aquí no aparece la idea de la línea sino, más bien, la del círculo, lo cíclico, la repetición: "Tu madre en la punta seca del compás / y el vuelo es el trazo de tiza. / Entonces no te acercas y / agoniza. No tienes la culpa, / eres culpable". ¿Por qué aparece aquí, en este contexto, este tema de la culpa?

-La culpa que no se tiene sino que se "es". Detrás de ese poema hay una anécdota, claro. Yo estaba en San Luis Potosí, adonde había ido por una de esas invitaciones inverosímiles que de tanto en tanto nos caen a los poetas. Había estado cuatro días en el corazón de la selva guasteca, en un pueblito que se llama Xilitla, a diez horas de viaje por carretera de la capital del estado. Cuando llego al aeropuerto para tomar el vuelo de vuelta a México D.F. abro mi portátil para ver si podía agarrar alguna red de wifi y revisar mi correo electrónico, y encuentro a mi madre conectada al Skype. En ese momento mi madre estaba haciendo un tratamiento médico muy severo, y como ella nunca quiso darse por enferma todos confiábamos o mejor dicho todos nos solidarizábamos con su manera frontal de negar la evidencia y de creer en la recuperación. Pero ese día, sentado en el minúsculo aeropuerto de San Luis Potosí, y hablándole al micrófono de una computadora portátil, medio escondiéndome detrás de la pantalla para evitar la mirada de los otros pasajeros que esperaban en la sala de embarque, tuve la evidencia, por la voz de mi madre, de que no se iba a recuperar, de que el final había empezado. Creo que, antes de sentir dolor o miedo, o quizás para no sentir dolor o miedo, me sentí culpable; supongo que culpable de estar ahí, en ese aeropuerto, en lugar de estar al lado de mi madre; o de seguir en movimiento cuando ella entraba o empezaba a entrar en la quietud. Es algo parecido, creo, a lo que le pasa a ese personaje que se llama Borges en la "candente mañana de febrero" en que comienza "El Aleph" : más que triste o abrumado por la muerte de Beatriz, Borges está enojado contra quienes cambian los carteles publicitarios de la Plaza Constitución : "el hecho me dolió, pues comprendí que el incesante y vasto universo ya se apartaba de ella y que ese cambio era el primero de una serie infinita". Bueno, lo que Borges, con su estilo un poco resabido (como dice Martínez Sarrión), sublima en el enojo contra un cartel publicitario es quizás algo cercano a lo que ahí, en el poema de cosas, aparece como culpa encarnada o incluso lo que, al final de El proceso, aparece como "vergüenza" : mientras a K. le 
atornillan un puñal en el corazón, el narrador dice : "fue como si la vergüenza debiera sobrevivirlo". Él estaba obligado a sentir la vergüenza que sus verdugos no podían conocer. No intento en ningún caso insinuarme a la altura de esos ejemplos sino señalar entonaciones que, precisamente por su grandeza definitiva, obran como diapasones de la memoria estética.

- Me gustaría que me hablaras, al menos dos palabras, de tu próximo proyecto, del que aparece un adelanto en 2010, en el n 80 de Diario de Poesía : "Vicisitudes de Jrest". Por lo que este adelanto deja entrever, y más allá de toda vicisitud de la escritura, este proyecto se presenta como algo totalmente diferente de lo anterior (particularmente de Cosas): estamos ante un poema único, extenso, continuo, a la manera de lo que Saer denomina (pensando en los poemas extensos de Juan L. Ortiz), "poesía narrativa"...

-Sí, es lo que estoy trabajando ahora, es el intento de poema extenso que pueda avanzar como un magma omnívoro. Tiene que ver con Juan L. porque el río, en este caso el Paraná, está muy presente. Pero creo que a la vez está muy lejos de Juan L., porque aquí el río es evocado ; no tiene esa presencia constante, precisa, material que tiene el río en Juan L. Tendría que mencionar, en todo caso, el río historiado de 40 Watts de Oscar Taborda, con los tobas en la barranca, o el delta con sus mil cursos severos y castigadores de Haroldo Conti, y sin duda el río remontado por la historia -nacional y personal - de Saer en El río sin orillas. Tengo todo ese sistema presente, aunque el poema que yo estoy escribiendo, salvo en determinados núcleos, no creo que sea narrativo. Asimilo la idea de poema narrativo con las grandes novelas en verso del siglo XIX, como Eugenio Oneguin o Don Juan de Byron. Por cierto, ya que mencionaste a Saer, creo que él sí tenía la fantasía de escribir una novela en verso, aunque no sé si llegó a plantearse alguna vez seriamente ese proyecto. En mi Jrest no hay entramado diegético, o si lo hay es como algo que sucedió y que apenas deja huella en el poema, es su pretexto. Sin embargo, aunque resulte algo contradictorio, debo decir que esa ambición o esa potencia de los grandes poemas narrativos del XIX siempre me atrajo, sobre todo en Byron. Cada uno de los románticos ingleses escribe su poema extenso : Wordworth hace en el Preludio un gran conglomerado autobiográfico ; Blake escribe el Matrimonio del Cielo $y$ del Infierno, su respuesta a Milton, que era su verdadera obsesión; Keats escribe Endymion, donde lo lírico es intenso pero queda un poco abrumado por una extensión extática. Seguramente el más poderoso, como conjunto, es el Prometeo liberado de Shelley, que es uno de los grandes manifiestos románticos, como la Balada del viejo marinero de Coleridge. Pero yo siempre tuve una particular debilidad por Don Juan, sobre todo los dos primeros cantos, los más extensos, que Byron escribe hacia 1819. Impresiona pensar que, para entonces, Byron ya se toma el romanticismo un poco en broma porque su héroe es deliberadamente débil, un muñeco en manos del destino (y el destino, a su vez, en mano de las mujeres). Don Juan es el primer gran poema de la digresión y de la parodia de sí mismo, es un poema que está siempre a punto de empezar y nunca termina de empezar porque el propio poeta interrumpe la acción con sus reflexiones, chismes, difamaciones de sus colegas y de los editores, apelaciones al lector... Hay una tensión entre exceso y medida muy atractiva, muy inteligente. Los estudiosos del mito de Don Juan tienden a desdeñar a Byron señalando que, en él, el mito es un mero pretexto para poner en movimiento una maquinaria que funcionaría igual aunque el asunto fuera otro, o ninguno. Yo creo que se equivocan : creo que en ese exceso, en esa ansiedad por avanzar desbordándose y haciendo rodeos hay algo esencialmente donjuanesco (a decir verdad, uno de mis proyectos actuales es un ensayo en el que pretendo mostrar esto, este último verano estuve tomando notas al respecto). 
Vuelvo ahora a mi Jrest : mi intención es trabajar en este caso en un remedo de bigbang : a partir de un primer estallido ir generando las ondas expansivas, los cuerpos, las órbitas. Pero el acento es siempre lírico, incluso cuando es una parodia de los recursos líricos. Quiere ser algo como lo que Ashbery llama "la gran ensalada" (yo también lo llamo "la mezcladora", un dispositivo en el que uno puede ir tirando paladas de cemento, de arena, de cal) : una construcción en la que quepa todo o casi todo, a fuerza de que uno sepa amasar y hornear una forma más o menos equilibrada. Ya veremos qué sale, por ahora tengo algo así como un tercio de lo que debiera ser el poema entero, y me gusta la forma que va cobrando.

\section{AUTOR}

\section{SERGIO DELGADO}

Escritor, Université Bretagne-Sud 